\title{
Primary Concurrent Chemoradiation in Head and Neck Cancers with Weekly Cisplatin Chemotherapy: Analysis of Compliance, Toxicity and Survival
} \author{
John Kelly ${ }^{1}$ Werner Dobrowsky ${ }^{1}$ Charles Kelly ${ }^{1}$ \\ ${ }^{1}$ Department of Clinical Oncology, Northern Centre for Cancer Care, \\ Newcastle upon Tyne, United Kingdom of Great Britain and Northern \\ Ireland \\ 2 Department of Clinical Oncology, Ninewells Hospital, Dundee, \\ Dundee, United Kingdom of Great Britain and Northern Ireland \\ 3 Department of Clinical Oncology, Clinical Oncology, Addenbrookes \\ Hospital, Cambridge, Cambridgeshire, United Kingdom of Great \\ Britain and Northern Ireland \\ ${ }^{4}$ Department of Research, Northern Centre for Cancer Care, \\ Newcastle upon Tyne, United Kingdom of Great Britain and Northern \\ Ireland
}

Muhammad Shahid Iqbal ${ }^{1}$ Cheng Chaw ${ }^{2}$ Josef Kovarik ${ }^{1}$ Shahzeena Aslam ${ }^{3}$ Aaron Jackson ${ }^{4}$

\begin{abstract}
Address for correspondence Muhammad Shahid Iqbal, FRCR, Department of Clinical Oncology, Northern Centre for Cancer Care, Freeman Hospital, Newcastle upon Tyne NE7 7DN, United Kingdom of Great Britain and Northern, Ireland (e-mail: shahid.iqbal@nhs.net).
\end{abstract}

Int Arch Otorhinolaryngol 2017;21:171-177.

\begin{abstract}
Keywords

- head and neck neoplasms

- chemoradiotherapy

- cisplatin

Introduction Concurrent chemoradiation is the standard of care in inoperable locally advanced squamous cell head and neck cancers. The most widely accepted schedule of concomitant cisplatin is $100 \mathrm{mg} / \mathrm{m}^{2}$ given on a 3 weekly basis but the optimal regime is unknown.

Objective The objective of this study is to assess the tolerability, compliance, and clinical outcomes of weekly cisplatin $\left(40 \mathrm{mg} / \mathrm{m}^{2}\right)$.

Methods During the period of January 2007-December 2009, we analyzed retrospectively 122 patients with histologically proven squamous cell carcinoma of head and neck (nasopharynx, oropharynx, larynx, hypopharynx, and oral cavity) treated with definitive chemoradiation. All patients received 63 Gy in 30 daily fractions with concomitant weekly cisplatin $40 \mathrm{mg} / \mathrm{m}^{2}$. We assessed treatment toxicities and patient compliance. We estimated overall survival using the Kaplan-Meier method.

Results Sixty-eight percent of patients managed to complete all six cycles of chemotherapy while $87 \%$ of patients completed at least 5 cycles of weekly cisplatin. Incidence of grade $3 / 4$ toxicity was as follows: mucositis $33 \%$, dermatitis $41 \%$, dysphagia $15 \%$, mouth/neck pain $17 \%$, neutropenia $2 \%$, and renal impairment $3 \% .53 \%$ patients required at least one hospital admission for symptom control. The 5 -year overall survival rate was $60 \%$.

Conclusion Concurrent chemoradiotherapy using weekly cisplatin at $40 \mathrm{mg} / \mathrm{m}^{2}$ per week is an effective, well tolerated regimen allowing most patients to receive at least 5 cycles of chemotherapy. However, a phase III randomized control trial comparing the standard dose of $100 \mathrm{mg} / \mathrm{m}^{2}$ cisplatin tri-weekly with a weekly regimen is needed to establish the long term clinical outcome.
\end{abstract}

received

April 11, 2016

accepted

September 9, 2016

published online

December 19, 2016
DOI http://dx.doi.org/

10.1055/s-0036-1594020.

ISSN 1809-9777.
Copyright $\odot 2017$ by Thieme-Revinter

Publicações Ltda, Rio de Janeiro, Brazil
License terms

(c) (i) $\ominus$ (\$) 


\section{Introduction with Objectives}

Head and neck cancers (HNC) are heterogeneous group of cancers and as a whole, they are the fifth most common cancer worldwide with an estimated annual global incidence of over half a million. ${ }^{1}$ Treatment approaches vary depending upon the location of the tumor, staging, and individual patient's characteristics. Optimal treatment for locally advanced HNC remains a challenge and concurrent chemoradiotherapy is the established standard of care for patients with inoperable disease or patients in whom surgery would be associated with unacceptable morbidity. The main treatment modality is external beam radiotherapy with or without chemotherapy. The most commonly used chemotherapeutic agent is cisplatin. The additional absolute benefit in overall survival of adding platinum based chemotherapy has been best estimated as $6.5 \%$ at 5 years when compared with radiotherapy alone. ${ }^{2}$ The optimal regimen of cisplatin is yet to be defined. However, the most widely used concurrent chemoradiation schedule uses high-dose bolus cisplatin $100 \mathrm{mg} / \mathrm{m}^{2}$ every three weeks, in combination with standard radiotherapy. ${ }^{3-6}$ The addition of concurrent chemotherapy to high dose external beam radiotherapy is often associated with increased toxicity and affects patient compliance with treatment completion. It also often involves an in-patient stay in the hospital for chemotherapy, which could potentially result in treatment delays.

Weekly cisplatin $40 \mathrm{mg} / \mathrm{m}^{2}$ has been the standard regimen for concurrent chemoradiotherapy for HNC at our institution. This retrospective study attempts to review the experience of external beam radiotherapy (63 $\mathrm{Gy}$ in 30 daily fractions) with concurrent weekly cisplatin $40 \mathrm{mg} / \mathrm{m}^{2}$. The objective of this retrospective study was to review the efficacy of this regime, evaluating the treatment response, patient compliance, toxicities, and outcomes of the treatment. We have also investigated the prognostic factors affecting the clinical outcome.

\section{Methods}

\section{Patient Population}

Patients with head and neck cancers who underwent definitive primary chemoradiotherapy over a period of three years (January 2007-December 2009) were identified from our department database. We only included patients with a histologically proven squamous cell carcinoma of the nasopharynx $(n=7)$, oropharynx $(n=74)$, larynx $(n=12)$, hypopharynx $(n=16)$ and oral cavity $(n=13)$. We excluded patients with primary tumors of salivary glands, nasal cavity, paranasal sinuses, and unknown primaries or patient with non-squamous cell carcinomas. We also excluded from the study patients treated adjuvantly or those who received chemotherapy other than weekly cisplatin. In total, there were 16 patients who received chemotherapy other than weekly cisplatin. Out of these 16 patients, 12 (oropharynx, $n=5$; hypopharynx, $n=3$; oral cavity, $n=3$, larynx, $n=1$ ) received treatment with mitomycin $\mathrm{C}$. Of these 12 patients, ten were with stage IV. Seven patients died. The median survival of this cohort was 58 months. One patient, a 57-year-old man with T2N2 oropharyngeal carcinoma, received cetuximab. He remained alive after five years of follow-up. The remaining three patients received carboplatin. Of these three patients, two presented with stage IV disease with mixed histology of squamous and small cell carcinoma. Both patients died after 4 and 6 months of diagnosis. Third patient with stage III nasopharyngeal carcinoma was lost to follow-up.

The clinical characteristics of the patients are summarized in - Table 1 . The median age was 57 years (range: $35-79$ ). The majority of the patients had locally advanced disease $(72 \%$ patients with stage IVa disease followed by $22 \%$ patients with stage III disease, - Table 2). A significant number of patients (82\%) had WHO performance status, 0 or 1 . Seventy-nine patients were smokers or past smokers which represented $65 \%$ of the entire group.

\section{Pre-treatment Evaluation}

All patients underwent clinical evaluations by the otolaryngologic-surgical team. Pre-treatment investigations included clinical history and examination, biopsies, imaging ( $\mathrm{CT} \pm \mathrm{MRI}$ and/or CT/PET scan), fitness evaluation with WHO performance status, and ACE-27 (Adult comorbidity evaluation). ${ }^{7} \mathrm{~A}$ multidisciplinary team comprising of otolaryngologists, clinical oncologists, radiologists, pathologist, dental and plastic surgeons, clinical nurse specialists, dieticians, and speech and language therapists met and discussed all patients. The treatment decisions were tailored individually based on clinical staging, comorbidities, long term functional outcome, and patient's choice.

\section{Chemotherapy}

We administered weekly intravenous cisplatin in outpatient day case settings with a dose of $40 \mathrm{mg} / \mathrm{m}^{2}$. We capped the maximum dose at $70 \mathrm{mg}$. Patients received a pre- and posthydration of $1000 \mathrm{~mL}$ of sodium chloride $0.9 \%$. Ten mmol of magnesium sulfate and $20 \mathrm{mmol}$ of potassium chloride were added in the post-hydration saline. Standard prophylactic antiemetic protocol was a combination of 5-hydroxytryptamine-3 (5HT3) - antagonists (ondansetron) and dexamethasone.

\section{Radiotherapy Schedule}

All patients were treated in a supine position, immobilized with a customized 5-point beam directed shell. The target volume definition was performed using Oncentra MasterPlan (Nucletron B.V. Veenedaal, Netherlands) Treatment Planning System, and the radiation treatment was delivered using step and shoot intensity modulated radiotherapy (IMRT). All patients received $63 \mathrm{~Gy}$ in 30 daily fractions over six weeks to the primary tumor site and involved neck nodes. This was just post-transitional period of switching from 3D conformal radiotherapy to IMRT for head and neck cancers in our department so the dose was kept at $63 \mathrm{~Gy}$. However, later the dose was increased to $65 \mathrm{~Gy}$ in 30 fractions, which is our standard regime now. The uninvolved contralateral neck nodes that carried an occult metastatic risk greater than $15 \%$ received a prophylactic dose of $54 \mathrm{~Gy}$ in 30 fractions. Radiotherapy was delivered with 6-MV photons using linear accelerators. 
Table 1 Summary of the patients and their disease characteristics

\begin{tabular}{|c|c|c|}
\hline & $n$ & $\%$ \\
\hline Total number of patients & 122 & - \\
\hline Male/Female & $97 / 25$ & $80 / 20$ \\
\hline Median age (years with range) & $57(35-79)$ & - \\
\hline \multicolumn{3}{|l|}{ Disease location } \\
\hline Nasopharynx & 7 & 6 \\
\hline Oropharynx & 74 & 61 \\
\hline Larynx & 12 & 10 \\
\hline Hypopharynx & 16 & 13 \\
\hline Oral cavity & 13 & 11 \\
\hline \multicolumn{3}{|l|}{ Stage } \\
\hline I & 1 & 1 \\
\hline II & 6 & 5 \\
\hline III & 27 & 22 \\
\hline IV & 88 & 72 \\
\hline \multicolumn{3}{|l|}{ WHO performance status } \\
\hline 0 & 70 & 57 \\
\hline 1 & 30 & 25 \\
\hline 2 & 19 & 16 \\
\hline 3 & 3 & 3 \\
\hline \multicolumn{3}{|l|}{ ACE-27 } \\
\hline 0 & 90 & 74 \\
\hline 1 & 18 & 15 \\
\hline 2 & 10 & 8 \\
\hline 3 & 4 & 3 \\
\hline \multicolumn{3}{|c|}{ Number of weekly cisplatin chemotherapy cycles completed } \\
\hline 6 & 83 & 68 \\
\hline 5 & 23 & 19 \\
\hline 4 & 6 & 5 \\
\hline 3 & 7 & 6 \\
\hline 2 & 3 & 3 \\
\hline \multicolumn{3}{|l|}{ Treatment outcome } \\
\hline Response assessable & 120 & 98 \\
\hline CR & 92 & 75 \\
\hline RD (clinically suspicious) & 28 & 23 \\
\hline Salvage surgery & 18 & 15 \\
\hline Pathological CR & 11 & $\begin{array}{l}61 \\
\text { (of } 18 \\
\text { patients) }\end{array}$ \\
\hline Confirmed RD & 7 & $\begin{array}{l}39 \\
\text { (of } 18 \\
\text { patients) }\end{array}$ \\
\hline \multicolumn{3}{|c|}{ Local recurrences (out of 120 evaluable patients) } \\
\hline No & 97 & 81 \\
\hline Yes & 23 & 19 \\
\hline Distant metastases & & \\
\hline
\end{tabular}

(Continued)
Table 1 (Continued)

\begin{tabular}{|l|l|l|}
\hline \multicolumn{1}{|l|}{} & $\boldsymbol{n}$ & $\%$ \\
\hline No & 108 & 90 \\
\hline Yes & 12 & 10 \\
\hline Survival (of total 122 patients) & 73 & 60 \\
\hline Alive & 73 & 40 \\
\hline Dead & 49 & \\
\hline
\end{tabular}

Abbreviations: $\mathrm{n}$, total number of patients; ACE-27, Adult Comorbidity Evaluation-27 as per RTOG guidelines ${ }^{7}$; CR, complete response; RD, residual disease.

\section{Toxicity Evaluation}

We assessed all patients on treatment on a weekly basis in a review clinic comprising clinical oncologists/specialist registrars, clinical nurse specialists, dietician, speech and language therapists, and a dental hygienist. We assessed and graded the treatment toxicities according to the radiation therapy oncology group (RTOG) and common toxicity criteria (CTCAE) guidelines. ${ }^{7}$ We recorded performance status, mucosal reaction, skin reaction, full blood count, urea and electrolytes, and liver function tests. Patients were considered unfit for chemotherapy in the case of deterioration of performance status, deterioration of kidney function (GFR $<50 \mathrm{~mL} / \mathrm{min}$ ), or blood count (absolute neutrophil count $<1.5$ and platelets $<100$ ). For patients who we found to be unfit for a cycle of chemotherapy we omitted that particular cycle altogether. No dose reductions were planned.

\section{Outcome Evaluation}

Six weeks after completion of treatment, all patients were assessed in a joint Head and Neck clinic with the otolaryngology surgical team. We clinically assessed response (clinical examination followed by laryngoscopy with fiber optic laryngoscope). Subsequent follow-up visits were scheduled on three monthly basis for the first year, a 3 to 6 monthly basis for the second year and a 6-monthly thereafter for a total period of five years. Radiological imaging (CT or PET/CT) and biopsies were performed if patients were found to have any suspicion of recurrence.

\section{Data Collection and Statistical Analysis}

We collected the data retrospectively and analyzed the results using SPSS version 21. Overall survival (OS) was defined as the time between the dates of tissue diagnosis to the dates of death/last seen in clinic. Kaplan-Meier estimates were performed to calculate the OS. The compliance of the patients to chemotherapy treatments were measured in terms of numbers of cycles completed. We reviewed hospital admission rates during chemoradiation treatment and evaluated factors that resulted in poor treatment compliance. Univariate analysis with log rank test was performed to study different factors correlating to survival and a $p<0.05$ was considered statistically significant. 
Table 2 Tumor, node, and metastases (TNM) staging and T stage of each subsite $(n=122)$

\begin{tabular}{|l|l|l|l|l|l|l|}
\hline \multicolumn{7}{|c|}{} \\
\hline & N0 & N1 & N2a & N2b & N2c & N3 \\
\hline T1 & 1 & 4 & 3 & 6 & 1 & 1 \\
\hline T2 & 5 & 9 & 5 & 8 & 4 & 1 \\
\hline T3 & 10 & 6 & 2 & 6 & 6 & 2 \\
\hline T4 & 9 & 7 & 8 & 9 & 9 & 0 \\
\hline T stage & Nasopharynx & Oropharynx & Larynx & Hypopharynx & Oral cavity \\
\hline T1 & 0 & 15 & 0 & 1 & 0 \\
\hline T2 & 4 & 18 & 2 & 5 & 3 \\
\hline T3 & 1 & 18 & 7 & 4 & 2 \\
\hline T4 & 2 & 23 & 3 & 6 & 8 \\
\hline
\end{tabular}

\section{Results}

\section{Clinical Outcome: Treatment Compliance and Acute Toxicities}

Of 122 total patients, all but two patients completed radiotherapy. Of these two patients, one patient developed an acute cerebrovascular event while on treatment and the second patient required a prolonged hospital admission due to pneumonia. Two thirds (68\%) of patients managed to complete all six cycles of weekly cisplatin chemotherapy as shown in - Table 1. Overall, $87 \%$ of patients managed to receive at least 5 cycles, that is, a cumulative dose of $200 \mathrm{mg} / \mathrm{m}^{2}$. The remaining $13 \%$ of patients received 2-4 cycles of weekly cisplatin. The incidence of grade 3 or 4 toxicities was as follows: mucositis (33\%), dermatitis (41\%), dysphagia (15\%), mouth/neck pain (17\%), neutropenia (2\%), and renal impairment (3\%). These patients and details of their toxicities are outlined in - Table 3. Fortyseven percent of patients did not require hospital admission during the course of treatment. Forty percent of patients required one hospital admission for the management of their acute toxicities. The remaining $13 \%$ of patients required multiple hospital admissions (Range 2-4).

\section{Clinical Outcome: Response to the Treatment}

Response was assessable in 120 patients. Ninety-two patients (75\%) achieved a clinical complete response. There was a clinical suspicion of residual disease in twenty-eight patients (23\%) and, in this group, 18 patients were deemed fit for salvage surgery (surgery on primary site and neck dissection in 8 patients and neck dissection alone in 10 patients). Eleven patients had complete pathological response following surgery and, in the remaining seven patients, residual disease was confirmed.

\section{Survival}

Seventy-three (60\%) patients were alive at the time of analysis. Thirty-one patients (26\%) were found to have recurrent disease and out of these 31 patients, 19 had developed loco-regional
Table 3 Summary of toxicities

\begin{tabular}{|c|c|c|}
\hline Toxicity & $n$ & $\%$ \\
\hline \multicolumn{3}{|l|}{ Mucositis } \\
\hline Grade $1 / 2$ & 82 & 67 \\
\hline Grade 3 & 38 & 31 \\
\hline Grade 4 & 2 & 2 \\
\hline \multicolumn{3}{|l|}{ Dermatitis } \\
\hline Grade $1 / 2$ & 72 & 59 \\
\hline Grade 3 & 46 & 38 \\
\hline Grade 4 & 4 & 3 \\
\hline \multicolumn{3}{|l|}{ Dysphagia } \\
\hline Grade $1 / 2$ & 104 & 85 \\
\hline Grade 3 & 17 & 14 \\
\hline Grade 4 & 1 & 1 \\
\hline \multicolumn{3}{|l|}{ Mouth/neck pain } \\
\hline Grade $1 / 2$ & 71 & 58 \\
\hline Grade 3 & 18 & 14 \\
\hline Grade 4 & 3 & 3 \\
\hline \multicolumn{3}{|l|}{ Neutropenia } \\
\hline Grade $1 / 2$ & 26 & 21 \\
\hline Grade 3 & 1 & 1 \\
\hline Grade 4 & 1 & 1 \\
\hline Renal impairment & 3 & 3 \\
\hline \multicolumn{3}{|c|}{ Number of times of hospital admissions } \\
\hline None & 57 & 47 \\
\hline Once & 49 & 40 \\
\hline Twice & 7 & 6 \\
\hline Thrice & 6 & 5 \\
\hline Four times & 2 & 2 \\
\hline
\end{tabular}




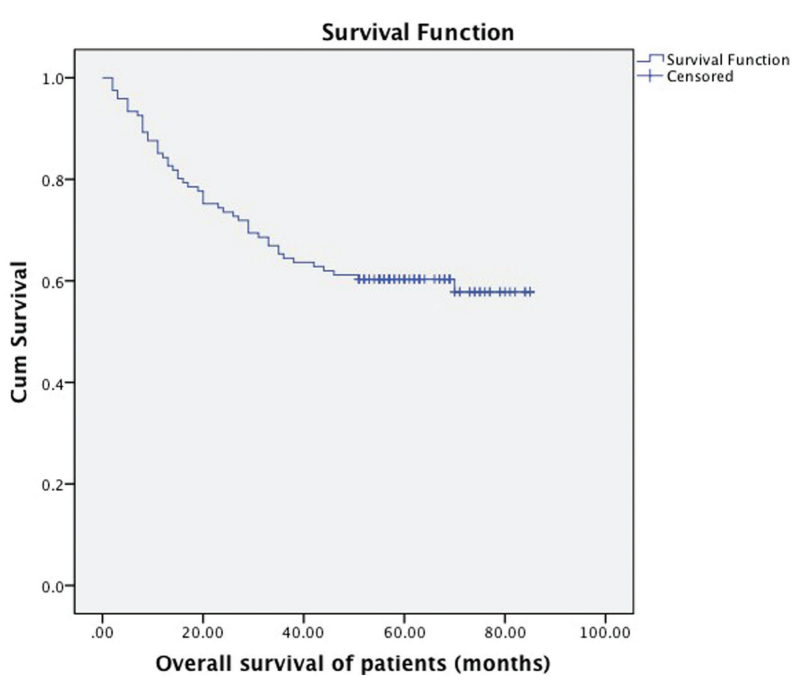

Fig. 1 Overall survival of all patients in the study with mean survival of 59 months (95\% Cl 53 - 64), with 73 patients alive and 49 censored cases.

recurrence, 8 patients had distant metastases, and 4 patients had developed both local recurrence and distant metastases. Overall and progression free survival rates are shown in - Figs. 1 and $\mathbf{2}$, respectively.

The authors also investigated the prognostic factors that affected the survival of patients in this study. We found that the WHO performance status ( $p<0.001$ ), stage of disease $(p<0.02)$, and tumor subsite (nasopharynx being the most favorable and oral cavity disease with worst prognosis, $p<0.02$, - Figs. 3 and 4 ) impacted on survival. However, gender $(p<0.7)$, age $(p<0.55)$, and number of chemotherapy cycles completed ( $p<0.11$ ) had no statistically significant impact on survival outcome.

\section{Discussion}

Definitive concurrent chemoradiotherapy is considered standard of care for inoperable locoregionally advanced head and

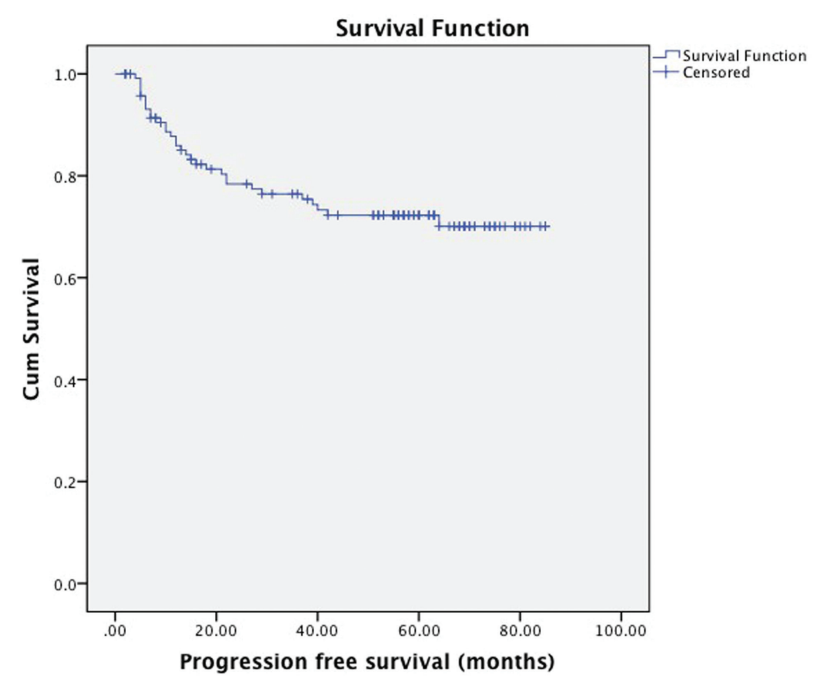

Fig. 2 Progression-free survival at 5 years (74\%), mean progression free survival of 66 months $(95 \% \mathrm{Cl} 60-71)$.

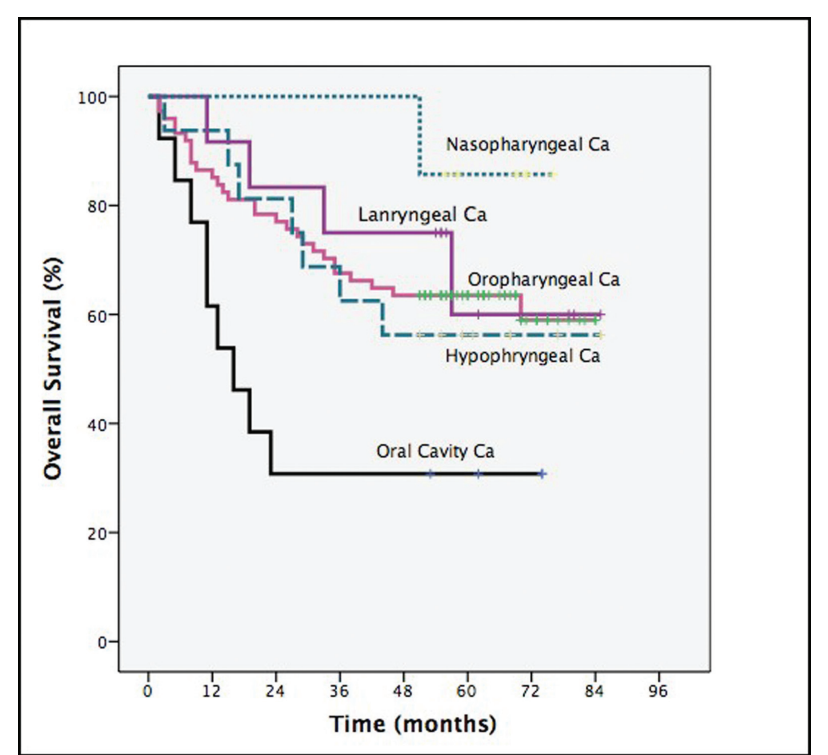

Fig. 3 Subgroup analysis of overall survival by different tumor sites.

neck squamous cell carcinomas. Cisplatin is the most common chemotherapeutic agent used in combination with radiotherapy. The underlying mechanism of cisplatin induced radiosensitization include inhibition of the repair of potentially lethal damage and sublethal damage, its ability to form DNA adducts and cell cycle arrest in G2 phase. ${ }^{8}$ The optimal regimen of concurrent cisplatin chemotherapy remains undefined, although the most robust evidence is the use of $100 \mathrm{mg} / \mathrm{m}^{2}$ cisplatin on a 3-weekly basis. However, this high dose cisplatin is associated with significant acute and late toxicities and the completion rate of the regime remains a challenge. ${ }^{3,9-12}$ Due to significant toxicities and poor compliance, there has been a trend toward the use of low dose

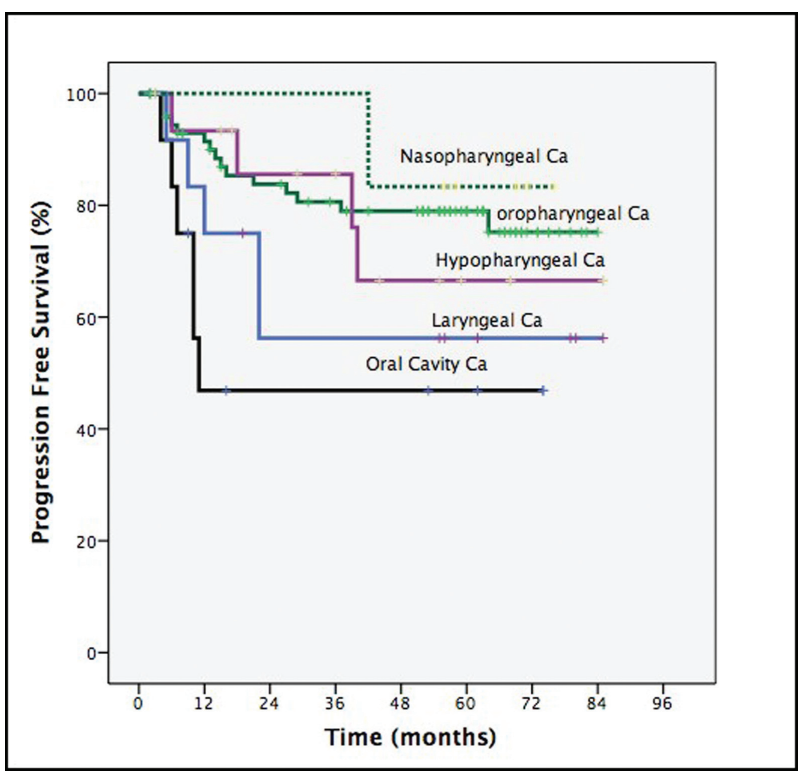

Fig. 4 Subgroup analysis of progression free survival by tumor subsites. 
weekly cisplatin concurrently with radiotherapy. There are no randomized trials to support to the use of low dose weekly cisplatin to date; published studies are limited to early phase studies and some small retrospective studies. There are several published studies with alternative cisplatin regimens such as $5-7 \mathrm{mg} / \mathrm{m}^{2} /$ day, 5 days a week during a 7 week course of fractionated radiotherapy, ${ }^{13-15} 5$ doses of $20 \mathrm{mg} / \mathrm{m}^{2}$ for 5 consecutive days, ${ }^{16}$ or $20 \mathrm{mg} / \mathrm{m}^{2}$ on 5 days of weeks 1 and $5^{17}$ during weeks 1,4 , and 7 of radiotherapy. Similarly, some studies evaluate the role of weekly cisplatin with the dose ranging from $30-60 \mathrm{mg} / \mathrm{m}^{2}$ for 6-7 weeks. ${ }^{18-24}$

In a prospective phase II trial by Sharma et al, weekly cisplatin $40 \mathrm{mg} / \mathrm{m}^{2}$ for 7 doses chemoradiotherapy $(n=77$; primary sites of oropharynx and nasopharynx) was compared against radical radiotherapy alone. Complete response was observed in $80.5 \%$ patients in the chemoradiotherapy group against $67.1 \%$ in the radiotherapy alone group $(p=0.04)$ however, this benefit was associated with frequent treatment interruptions (28.9\% versus $9.3 \% ; p=0.003$ ) and hospitalisation (40.8\% versus 20\%). The incidence of grade III and IV acute toxicity was $40 \%$ in the chemoradiotherapy group versus $20 \%$ in the radiotherapy alone group $(p=0.015) .^{19}$

Uygun et al studied two different regimes of cisplatin in a retrospective analysis. They reviewed weekly $40 \mathrm{mg} / \mathrm{m}^{2}$ $(n=20)$ and 3-weekly regimen $(n=30)$ of cisplatin in two different population groups and there was a statistically similar response rate and a similar adverse event profile. ${ }^{25}$ However, in a retrospective study, Geeta et al reached a different conclusion: 3-weekly cisplatin was less toxic than a weekly regime $40 \mathrm{mg} / \mathrm{m}^{2}$, however, the number of patients in this group was small $(n=32) .{ }^{26}$ In another indirect retrospective comparison, Ho et al compared weekly cisplatin $33-40 \mathrm{mg} / \mathrm{m}^{2}$ $(n=24)$ with 3-weekly cisplatin $80-100 \mathrm{mg} / \mathrm{m}^{2}(n=27)$ with concurrent radical radiotherapy. More patients received a higher cumulative dose of at least $240 \mathrm{mg} / \mathrm{m}^{2}$ in the weekly arm as compared with the 3 -weekly cisplatin $(p=0.04)$. None of the patients in 3-weekly arm were able to receive the full three cycles $100 \mathrm{mg} / \mathrm{m}^{2}$ (maximum cumulative dose of 200 $\mathrm{mg} / \mathrm{m}^{2}$ ). Similarly, more delays ( $41 \%$ versus $29 \%$ ) and omission of chemotherapy (17.4\% versus 5.6\%) occurred in the 3-weekly compared with the weekly regime, however, toxicity, radiotherapy overall treatment time and delays were similar between the two groups. ${ }^{27}$

In one of the largest studies documenting single-center experience of weekly cisplatin $30 \mathrm{mg} / \mathrm{m}^{2}$ concurrently with radiotherapy ( $n=264$ ), Gupta et al found that with the regimen of 70 Gy given in 7 weeks, the median number of chemotherapy cycles was six (range 1-7). Two thirds (65\%) of the patients received $\geq 85 \%$ of the planned cisplatin dose. The incidence of acute grade $\geq 3$ toxicities of mucositis and dermatitis was present in $29 \%$ and $35 \%$ of patients, respectively. With a mean follow-up of 19 months, 5-year disease-free survival was $43 \%{ }^{21}$

In a recent phase II trial of comparison of weekly $\left(40 \mathrm{mg} / \mathrm{m}^{2}\right.$ for seven weeks) versus triweekly $\left(100 \mathrm{mg} / \mathrm{m}^{2}\right.$ three doses on a 3-weekly basis) in patients with locally advanced nasopharyngeal carcinoma ( $n=109$ ), weekly cisplatin was associated with improved quality of life without compromising the efficacy. The toxicity profile was similar in both treatment arms. ${ }^{28}$ In a recent study by Rivelli et al, the authors have extensively reviewed the incidence of late toxicities in head and neck cancer patients treated with cisplatin based chemoradiation. Dysphagia (25\%), xerostomia (40\% with IMRT), hypothyroidism (42\%), ototoxicity (27\%), and osteoradionecrosis (4\%) were the most frequently reported late toxicities. Old age, advanced T stage, larynx/hypopharynx primary, and neck dissection after chemoradiotherapy were found to be predictive of late toxities. $^{29}$

This current study is one of the largest from a European single center. Our findings support those by Gupta et al, the largest published single institutional study. Our study showed similar chemotherapy compliance with better outcomes. According to our experience, weekly cisplatin is easier to manage than 3-weekly cisplatin because of closer monitoring and its increased flexibility allows for easier dose adjustment or omission in response to patient morbidity. Homma et al reached the same conclusion in their study of 53 patients. ${ }^{12}$ In our study, 6 patients were with stage I/II, which may explain good survival.

We recognize the limitations of this study. First this is a retrospective study of patients with squamous cell carcinomas of five primary sites of the same region. Second human papilloma virus (HPV) status was not available for the patients with oropharyngeal disease as it was not routine practice in our institution at that time. Third, the chemotherapy dose was capped at a maximum of $70 \mathrm{mg}$ which potentially may have resulted in under dosage of some patients with increased body habitus. However, this capping of cisplatin dose may explain relatively less grade $\geq 3$ toxicities in our study compared with other studies with weekly cisplatin, as discussed above.

\section{Conclusion}

In conclusion, our study demonstrated weekly $\left(40 \mathrm{mg} / \mathrm{m}^{2}\right)$ cisplatin given concurrently with radiotherapy to a total dose of $63 \mathrm{~Gy}$ in 30 daily fractions over a period of six weeks can be safely administered with acceptable toxicity and without compromising efficacy. However, a phase III randomized control trial comparing the standard dose of $100 \mathrm{mg} / \mathrm{m}^{2}$ cisplatin tri-weekly with a weekly regimen is needed to establish the long term clinical outcome.

\section{References}

1 Parkin DM, Bray F, Ferlay J, Pisani P. Estimating the world cancer burden: Globocan 2000. Int J Cancer 2001;94(2):153-156

2 Pignon JP, le Maître A, Maillard E, Bourhis J; MACH-NC Collaborative Group. Meta-analysis of chemotherapy in head and neck cancer (MACH-NC): an update on 93 randomised trials and 17,346 patients. Radiother Oncol 2009;92(1):4-14

3 Adelstein DJ, Li Y, Adams GL, et al. An intergroup phase III comparison of standard radiation therapy and two schedules of concurrent chemoradiotherapy in patients with unresectable squamous cell head and neck cancer. J Clin Oncol 2003;21(1):92-98

4 Bernier J, Domenge C, Ozsahin M, et al; European Organization for Research and Treatment of Cancer Trial 22931. Postoperative irradiation with or without concomitant chemotherapy for locally advanced head and neck cancer. N Engl J Med 2004;350(19):1945-1952 
5 Cooper JS, Pajak TF, Forastiere AA, et al; Radiation Therapy Oncology Group 9501/Intergroup. Postoperative concurrent radiotherapy and chemotherapy for high-risk squamous-cell carcinoma of the head and neck. N Engl J Med 2004;350(19):1937-1944

6 Fountzilas G, Skarlos D, Kosmidis P, et al. Radiation therapy and concurrent cisplatin administration in locally advanced head and neck cancer. A Hellenic Co-operative Oncology Group study. Acta Oncol 1994;33(7):825-830

7 https://www.rtog.org/ResearchAssociates/AdverseEventReporting/CooperativeGroupCommonToxicityCriteria.aspx

8 Marcu L, van Doorn T, Olver I. Cisplatin and radiotherapy in the treatment of locally advanced head and neck cancer-a review of their cooperation. Acta Oncol 2003;42(4):315-325

9 Forastiere AA, Goepfert H, Maor M, et al. Concurrent chemotherapy and radiotherapy for organ preservation in advanced laryngeal cancer. N Engl J Med 2003;349(22):2091-2098

10 de Castro G Jr, Snitcovsky IM, Gebrim EM, et al. High-dose cisplatin concurrent to conventionally delivered radiotherapy is associated with unacceptable toxicity in unresectable, non-metastatic stage IV head and neck squamous cell carcinoma. Eur Arch Otorhinolaryngol 2007;264(12):1475-1482

11 Machtay M, Moughan J, Trotti A, et al. Factors associated with severe late toxicity after concurrent chemoradiation for locally advanced head and neck cancer: an RTOG analysis. J Clin Oncol 2008;26(21):3582-3589

12 Homma $\mathrm{A}$, Inamura $\mathrm{N}$, Oridate $\mathrm{N}$, et al. Concomitant weekly cisplatin and radiotherapy for head and neck cancer. Jpn J Clin Oncol 2011;41(8):980-986

13 Jeremic B, Shibamoto Y, Milicic B, et al. Hyperfractionated radiation therapy with or without concurrent low-dose daily cisplatin in locally advanced squamous cell carcinoma of the head and neck: a prospective randomized trial. J Clin Oncol 2000;18(7):1458-1464

14 Boulmay BC, Riggs CE, Lawson M, Morris C, Mendenhall WM. Validation of weekly-dose cisplatin combined with radiation therapy in locally advanced head and neck cancer [abstract]. Proc Am Soc Clin Oncol 2007;25(18S):6076

15 Hoebers FJ, Heemsbergen W, Balm AJ, van Zanten M, Schornagel $\mathrm{JH}$, Rasch CR. Concurrent chemoradiation with daily low dose cisplatin for advanced stage head and neck carcinoma. Radiother Oncol 2007;85(1):42-47

16 Lau H, Brar S, Hao D, MacKinnon J, Yee D, Gluck S. Concomitant low-dose cisplatin and three-dimensional conformal radiotherapy for locally advanced squamous cell carcinoma of the head and neck: Analysis of survival and toxicity. Head Neck 2006;28(3): 189-196

17 Huguenin P, Beer KT, Allal A, et al. Concomitant cisplatin significantly improves locoregional control in advanced head and neck cancers treated with hyperfractionated radiotherapy. J Clin Oncol 2004;22(23):4665-4673

18 Newlin HE, Amdur RJ, Riggs CE, Morris CG, Kirwan JM, Mendenhall WM. Concomitant weekly cisplatin and altered fractionation radiotherapy in locally advanced head and neck cancer. Cancer 2010;116(19):4533-4540

19 Traynor AM, Richards GM, Hartig GK, et al. Comprehensive IMRT plus weekly cisplatin for advanced head and neck cancer: the University of Wisconsin experience. Head Neck 2010;32(5): 599-606

20 Sharma A, Mohanti BK, Thakar A, Bahadur S, Bhasker S. Concomitant chemoradiation versus radical radiotherapy in advanced squamous cell carcinoma of oropharynx and nasopharynx using weekly cisplatin: a phase II randomized trial. Ann Oncol 2010; 21(11):2272-2277

21 Gupta T, Agarwal JP, Ghosh-Laskar S, Parikh PM, D'Cruz AK, Dinshaw KA. Radical radiotherapy with concurrent weekly cisplatin in loco-regionally advanced squamous cell carcinoma of the head and neck: a single-institution experience. Head Neck Oncol 2009;1:17

22 Boulmay BC, Chera BS, Morris CG, et al. Definitive altered fractionation radiotherapy and concomitant weekly cisplatin for locally advanced head and neck cancer. Am J Clin Oncol 2009;32(5): 488-491

23 Medina JA, Rueda A, de Pasos AS, et al. A phase II study of concomitant boost radiation plus concurrent weekly cisplatin for locally advanced unresectable head and neck carcinomas. Radiother Oncol 2006;79(1):34-38

24 Beckmann GK, Hoppe F, Pfreundner L, Flentje MP. Hyperfractionated accelerated radiotherapy in combination with weekly cisplatin for locally advanced head and neck cancer. Head Neck 2005; 27(1):36-43

25 Uygun K, Bilici A, Karagol H, et al. The comparison of weekly and three-weekly cisplatin chemotherapy concurrent with radiotherapy in patients with previously untreated inoperable non-metastatic squamous cell carcinoma of the head and neck. Cancer Chemother Pharmacol 2009;64(3):601-605

26 Geeta SN, Padmanabhan TK, Samuel J, Pavithran K, Iyer S, Kuriakose MA. Comparison of acute toxicities of two chemotherapy schedules for head and neck cancers. J Cancer Res Ther 2006;2(3): 100-104

27 Ho KF, Swindell R, Brammer CV. Dose intensity comparison between weekly and 3-weekly Cisplatin delivered concurrently with radical radiotherapy for head and neck cancer: a retrospective comparison from New Cross Hospital, Wolverhampton, UK. Acta Oncol 2008;47(8):1513-1518

28 Lee JY, Sun JM, Oh DR, et al. Comparison of weekly versus triweekly cisplatin delivered concurrently with radiation therapy in patients with locally advanced nasopharyngeal cancer: A multicenter randomized phase II trial (KCSG-HN10-02). Radiother Oncol 2016;118(2):244-250

29 Rivelli TG, Mak MP, Martins RE, da Costa e Silva VT, de Castro G Jr. Cisplatin based chemoradiation late toxicities in head and neck squamous cell carcinoma patients. Discov Med 2015;20(108): $57-66$ 